\title{
ENTREVISTA AL DOCTOR HÉCTOR FIX FIERRO ${ }^{1}$
}

\author{
ABRIL USCANGA BARRADAS
}

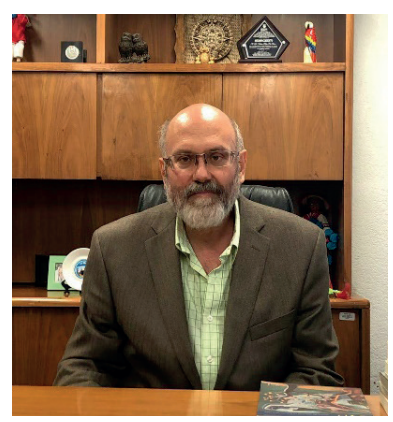

HÉctor Fix Fierro es Licenciado en Derecho por la Facultad de Derecho de la Universidad Nacional Autónoma de México (1987), Máster Internacional en Sociología Jurídica por el Instituto Internacional de Sociología Jurídica de Oñati, País Vasco, España (1994) y Doctor en Derecho por la Universidad de Bremen, Alemania (1998). Investigador de Tiempo Completo en el Instituto de Investigaciones Jurídicas de la UNAM (desde 1991); nivel y categoría Titular "C" (desde 2005); Investigador Nacional (desde 1999); nivel III desde 2010 y Profesor de la materia Sociología Jurídica en la Maestría en Derecho de la Facultad de Derecho de la UNAM (desde 2008). Fue Director del Instituto de Investigaciones Jurídicas de la UNAM (2006-2014). Sus principales líneas de investigación, con énfasis de carácter empírico, son la reforma de la justicia y los procesos de cambio jurídico en México.

${ }^{1}$ Este documento constituye una transcripción de la entrevista realizada. Se ha revisado sin alterar el estilo coloquial propio de una conversación, considerando que esta característica enriquecería el texto que se presenta al lector. La entrevista fue realizada con la colaboración de Mara Anahí Bernabe Galván, Salvador Villaseñor Olguín y Brenda Olalde Gómez. 
Entrevista al Doctor Héctor Fix Fierro $2 *$

Abril Uscanga Barradas: Muy buenas tardes, doctor Héctor Fix Fierro. Es un placer que haya aceptado el colaborar con la Revista del Posgrado en Derecho de la UNAM; para nosotros es un gran honor que haya accedido a realizar esta entrevista. Quisiéramos, si nos permite, hacerle algunas preguntas en relación a su trayectoria. Comenzaré con una pregunta que naturalmente está vinculada con su vida personal y familiar, ya que es difícil pensar, en algún momento, en separar, sin ningún reparo, su vínculo familiar con uno de los juristas más importantes que ha tenido este país: me refiero a su padre, el doctor Héctor Fix Zamudio. En ese sentido le agradecemos también si nos pudiera compartir un poco acerca de esta referencia familiar en alguna medida vinculada con su trayectoria académica. Quisiéramos saber, doctor, ¿cuándo inició su interés por el derecho?

Héctor Fix Fierro: Mi idea inicial era estudiar ciencias políticas, pero fue mi padre, el doctor Fix Zamudio, quien influyó, con el refuerzo de algunas amistades suyas, para que estudiara primero la carrera de derecho. La verdad es que me dejé convencer con cierta facilidad y no persistí en mi idea inicial, pensando que más adelante podría continuar con el plan de dedicarme a las ciencias políticas. No fue una mala decisión. Cursé la carrera de derecho sin dificultades y confieso que muchas asignaturas fueron motivantes. Sin embargo, una vez finalizada la licenciatura, me propuse hacer estudios de posgrado en Alemania con el profesor Reinhold Zippelius, quien era autor de un conocido libro de Teoría General del Estado, en la tradición alemana. Cuando era director de este Instituto, el doctor Jorge Carpizo me invitó a traducir el libro, tarea que inicié con la audacia del ignorante, incluso antes de comenzar mis estudios

$2^{*}$ El entrevistado agradece los atinados comentarios de Jacqueline Martínez Uriarte a la versión transcrita y revisada de la entrevista. 
profesionales. Me arrepentí varias veces de haber aceptado, pero al final concluí con éxito la traducción, que me sirvió de mucho. El profesor Zippelius me apoyó para iniciar estudios de doctorado con él en la Universidad de Erlangen-Nuremberg y escogí como tema la protección del ambiente como función descentralizada del Estado.

Después de dos años de estudios encaminados a cumplir varios requisitos previos al doctorado propiamente dicho, dejé de estar seguro de lo que estaba haciendo y regresé a México a empezar de nuevo, pero ya con una idea más precisa de lo que me interesaba: la llamada sociología jurídica o sociología del derecho. El doctor José Luis Soberanes, entonces director del Instituto, me apoyó para que ingresara como investigador de tiempo completo, con un proyecto sobre sociología de los derechos humanos, aunque pronto me encaminé hacia otros temas.

Al final, es en la sociología del derecho en lo que me he especializado, aunque realmente no he tenido mucha instrucción formal en la disciplina. Hice algunos cursos en el Instituto Internacional de Sociología Jurídica de Oñati y luego la tesis doctoral que presenté en la Universidad de Bremen, Alemania, bajo la dirección del profesor Volkmar Gessner, un sociólogo del derecho muy distinguido que falleció hace algunos años. Entonces, lo que he hecho es establecer un compromiso y un puente entre el estudio del derecho y el de otras ciencias sociales. Debo reconocer que, en este camino, ser hijo del doctor Fix Zamudio no me ha pesado, sino que, por el contrario, me ha abierto muchas puertas, me ha deparado numerosas amistades y me ha enriquecido personal y profesionalmente, por lo que solamente le puedo tener admiración y gratitud.

AUB: Ahora bien, durante su formación, ¿cómo siente usted que pudo ser influenciado hacia las líneas de investigación o hacia lo que actualmente usted ha trabajado desde la perspectiva jurídica, abonada con la sociología del derecho?, y ¿qué profesores o autores usted considera que han marcado su vida profesional? 
HFF: Cuando me fui inicialmente a hacer estudios en Alemania, descubrí por casualidad al gran sociólogo Niklas Luhmann, porque me interesaba el tema de la tecnocracia y ese parecía ser el centro de su famosa controversia con Jürgen Habermas (¡los textos de la polémica se publicaron en 1971 !). La verdad es que me deslumbró. $\mathrm{Al}$ principio no entendí nada de lo él escribía, pero perseveré y poco a poco fui comprendiendo su proyecto intelectual. El primer año casi lo dediqué a leer todo lo que pude de este autor, hasta el punto de que, con alguna preocupación, el profesor Zippelius -que lo conocía también y lo respetaba, aunque no compartía su radicalismo teórico- me decía, con alguna angustia, "por favor no demasiado Luhmann, señor Fix". Al final, Luhmann, quien era jurista de formación y tiene aportaciones sumamente relevantes a la sociología del derecho, se convirtió para mí en un referente teórico central. Veinte años después de su fallecimiento podríamos decir que ya pertenece al mainstream sociológico, pero a fines de los años ochenta era todavía un autor exótico y casi incomprensible (además, no había prácticamente traducciones al español de sus obras); ahora es un autor cada vez más conocido y reconocido, también en nuestra lengua, gracias, en buena parte, a la incansable labor que como traductor y editor ha realizado el profesor Javier Torres Nafarrate, de la Universidad Iberoamericana en Ciudad de México.

Todavía antes de viajar a Alemania, me encontré al profesor Gessner en un congreso al que nos había invitado a ambos el profesor Óscar Correas, entonces en la Universidad Autónoma de Puebla. Gessner me dijo que si no me hallaba con el profesor Zippelius, él me invitaba a hacer la tesis de doctorado en la Universidad de Bremen. Así fue, solamente que la tesis la escribí en México y fui luego a presentar allá el examen de grado. No obstante, me considero un discípulo fallido del profesor Gessner. Esto lo explico en un pequeño ensayo que escribí en recuerdo y aprecio de su vida y obra, 
el cual está incluido en un libro de homenaje a él que publicó el profesor Rafael Sánchez Vázquez, de la Universidad Autónoma de Puebla, y que también se encuentra reproducido en la revista electrónica Hechos y Derechos del Instituto de Investigaciones Jurídicas.

¿Cómo y por qué conocí al profesor Gessner? A él le debemos una investigación empírica pionera sobre la justicia en México, la que se convirtió en su tesis de habilitación, que es la tesis que se exige en Alemania para el desempeño de la cátedra universitaria. Gessner estuvo aquí en los años de 1969 y 1970. Él vino a averiguar qué conflictos había en el campo del derecho privado en México, que en Alemania incluye a los conflictos individuales del trabajo; fue un estudio netamente sociológico de cómo se producían, se desarrollaban y se resolvían tales conflictos. Para llevar a cabo el estudio, Gessner realizó numerosas entrevistas, analizó una muestra de expedientes judiciales e hizo una pequeña encuesta, en la ciudad de México, en Tepic y en otra pequeña población rural del estado de Nayarit.

Al llegar a México, Gessner se acercó al Instituto de Investigaciones Jurídicas. El doctor Fix Zamudio, que era entonces el director, lo apoyó y lo orientó en lo posible. También promovió que su libro, publicado en Alemania en 1976, se tradujera y apareciera en México, lo que sucedió hasta 1984 bajo el título de Los conflictos sociales y la administración de justicia en México, con traducción de la profesora Renate Marsiske (la obra está totalmente agotada, pero se encuentra consultable en la Biblioteca Jurídica Virtual). Siendo yo todavía estudiante y antes de la aparición de este libro, traduje, con la ayuda de mi padre, un ensayo del profesor Gessner que resumía los principales hallazgos de su investigación en México (el ensayo apareció en el Boletín Mexicano de Derecho Comparado en 1982). De ahí, pues, el vínculo personal que establecimos. 
En una visita que hizo a México en 1993, para estudiar el tema de la reforma judicial, el profesor Gessner me manifestó estar algo frustrado de que en nuestro país nadie parecía haber leído, entendido y aprovechado su libro, y eso me incluía a mí, que no lo había trabajado todavía con suficiente cuidado. Como detalle sobre el interés actual de esta obra, puedo comentar que hace unos años incluimos en la Encuesta Nacional de fusticia 2015, realizada aquí en el Instituto, una de las preguntas que Gessner utilizó para su encuesta en 1970. La pregunta decía más o menos así: “¿Usted piensa que los tribunales tratan a todas las personas con imparcialidad, o solamente con influencias y dinero se pueden ganar los juicios?" Entonces fue el 78 por ciento de los encuestados que se inclinó por la segunda opción; en nuestra encuesta, de alcance nacional, fue casi el 72 por ciento. Eso nos dice algo sobre la desconfianza que la justicia en nuestro país sigue generando.

Desde luego, el profesor Gessner no ha sido el único referente para mí. Otras figuras importantes, además de mi padre, han sido el doctor Jorge Carpizo y el doctor Diego Valadés, y algunos otros sociólogos del derecho que he llegado a conocer y tratar personalmente, como los profesores Rogelio Pérez Perdomo, de Venezuela, Lawrence Friedman, de la Universidad de Stanford, o Vincenzo Ferrari, de la Universidad de Milán. Como ya dije, yo ingresé como investigador al Instituto en 1991 y nunca me he planteado hacer otra cosa en mi vida. A mi edad ya veo también difícil empezar a buscar otros horizontes profesionales.

AUB: Le agradecemos mucho que nos comparta su formación profesional y los autores y personajes que han marcado su vida. Doctor, ¿sería posible que nos compartiera alguna vivencia que haya tenido con su padre?

HFF: Es difícil; tendría que ponerme a pensar un poco, ya que obviamente a lo largo de los años hemos platicado mucho. Recuer- 
do que cuando estaba estudiando la carrera, a veces llegaba a casa un poco desalentado, porque no todos los profesores eran lo que yo esperaba. Él me decía, para animarme, que en su época era igual, que también había toda clase de profesores en la Escuela Nacional de Jurisprudencia. Yo le replicaba, con ánimo un poco contestatario, que en ese tiempo había grandes maestros, como Felipe Tena Ramírez, Gabino Fraga, Mario de la Cueva, Antonio Carrillo Flores y otros muchos, y que ya en mi época no contábamos con esta pléyade tan distinguida. Yo me inscribía en ocasiones con profesores que eran para mí desconocidos y que luego me daban una agradable sorpresa, pues estaban muy comprometidos con su materia y le despertaban a uno interés y gusto por ella. En la época de mis estudios quizá ya no estaba activa la excepcional generación de maestros de los años cuarenta y cincuenta, pero seguía habiendo profesores muy destacados. Recuerdo, por ejemplo, el intenso curso de derecho constitucional que llevé con el doctor Jorge Carpizo, o los estimulantes cursos de introducción al estudio del derecho y filosofía del derecho que impartía el doctor Rolando Tamayo y Salmorán.

AUB: Gracias por compartirlo, doctor. En ese mismo sentido, usted ha llevado una carrera parecida a la de su padre en el ámbito académico, casi totalmente desarrollado desde una perspectiva universitaria. Ambos han sido directores del Instituto de Investigaciones Jurídicas y eminentes juristas, muy reconocidos. Quiero preguntarle, doctor, ¿qué ha significado para usted la UNAM?

HFF: Desde que entré a la carrera, no he vuelto a salir de la Universidad. La UNAM es mi casa académica. Es una Universidad muy grande y mi conocimiento sobre ella sigue siendo limitado; si acaso puedo decir que conozco más o menos bien este Instituto. Mi conocimiento de la UNAM se amplió en la época en que fui director y tuve otras responsabilidades universitarias. Una que recuerdo ha- 
ber cumplido con mucho entusiasmo, fue la presidencia de la Comisión de Legislación Universitaria del Consejo Universitario. Ahí nos tocó revisar, para su aprobación por el Consejo, varios reglamentos muy importantes, entre ellos el Reglamento General de Estudios Universitarios, que no existía hasta entonces, o el Reglamento para la Elección de Consejeros Universitarios y Técnicos. Fue una gran experiencia que me permitió interactuar con profesores y alumnos de otras entidades de la UNAM.

Para mí, la Universidad es una institución muy especial, un microcosmos del país, porque tanto las virtudes como los defectos de nuestra sociedad se reflejan aquí de manera inmediata. Se podría decir que es también una especie de sismógrafo, ya que los movimientos que se dan fuera también se sienten aquí dentro, y por ello la comunidad universitaria ha tenido sus conflictos y desencuentros. Cuando yo era todavía estudiante estalló la huelga, que duró solamente unas semanas, del Consejo Estudiantil Universitario (CEU), pero nosotros estábamos del lado del doctor Carpizo y pretendíamos apoyarlo. Aunque el conflicto despertó en nosotros fuertes pasiones, acabamos por aceptar que estos conflictos son reflejo de la pluralidad de la Universidad, y que es positivo que no estemos todos de acuerdo con una sola idea. Cuando han ocurrido estos paros, hemos podido restablecer el trabajo universitario, pero siempre esperamos que estos episodios del pasado no se repitan.

AUB: Dentro de todo este ámbito universitario, usted en realidad se ha determinado a hacer una vida de investigación, aunque no ha excluido de ninguna forma la docencia, ¿Qué es lo que más disfruta de la investigación?, ¿cuál fue ese razonamiento que lo guio a la labor de investigación?

HFF: No sé realmente si tomé una decisión muy consciente para ser investigador, pero la verdad, nunca consideré seriamente otras opciones profesionales. Jamás he pisado un despacho como pasante 
o como abogado; tampoco me he planteado desempeñar un cargo en la judicatura, y mucho menos he aceptado ocupar algún puesto de gobierno, pero no porque desprecie estas actividades. He sido muy feliz como investigador y, de hecho, el día de hoy (15 de agosto de 2019) cumplo exactamente 28 años en esta función. Sin duda el tiempo pasa rápidamente.

Me gusta mucho hacer la "talacha" académica, las humildes tareas de búsqueda de materiales, de elaboración de resúmenes, de preparación de bases de datos, de análisis de la información recopilada, que aparentemente quitan tiempo a las funciones más elevadas de pensar y escribir. Por eso no he podido acostumbrarme a tener becarios o asistentes de investigación que me ayuden. Prefiero hacer todo yo mismo, aunque cometa errores o sea ineficiente, porque me permite irme dando cuenta de las ideas que podría manejar o desarrollar. Antes me angustiaba tener que escribir, presionado por la necesidad de encontrar la estructura adecuada y la expresión justa, así que sentarme a hacerlo no era realmente placentero. Sin darme cuenta, eso ha cambiado de unos años para acá. Ahora me siento a escribir y me salen los textos con cierta facilidad. Me doy cuenta que eso se debe en parte a que, en tantos años, he acumulado una buena cantidad de conocimientos y de referencias científicas que puedo usar y combinar. Creo que es una ventaja de las ciencias sociales y las humanidades que el conocimiento sea acumulativo y que con la edad haya cada vez más posibilidades de hacer un trabajo igualmente extenso y profundo. Ahora hasta me divierte escribir. No voy a decir que llene cientos de cuartillas al año, porque no es el caso, pero creo que me defiendo en el promedio. También disfruto revisando materiales históricos, como los informes de la Suprema Corte, o el Diario Oficial de la Federación, de donde extraigo en ocasiones notas o anécdotas que pueden hacer un poco más atractivos mis trabajos. 
AUB: 28 años implica una gran trayectoria. El recorrido que ha tenido es ejemplar, doctor. La verdad yo creo ha tenido una gran dedicación.

HFF : Es perseverancia. Cuando mi padre cumplió noventa años y le hicimos un homenaje aquí en el Instituto, el día anterior a que yo concluyera mis funciones como director, dijo él que su único mérito era la perseverancia, pues estaba cumpliendo casi sesenta años ininterrumpidos como investigador universitario. Es la perseverancia la que permite acumular conocimientos y hacer muchas cosas con ellos. Yo respeto mucho a mis colegas que aceptan funciones y encargos externos ya que también es importante comprometerse con las necesidades del país, e incluso he escrito sobre eso, pero creo que la investigación es celosa y si uno la deja un tiempo, cuesta trabajo regresar a ella. Entonces, aunque he hecho algunas labores adicionales fuera de la Universidad, nunca he estado lejos de los temas académicos y nunca he dejado la investigación y si ahora puedo hacer ciertas cosas, es gracias a esos años y a esa acumulación.

AUB: Considero que en gran medida la obra académica que se realiza en toda la Universidad, repercute a nivel nacional y a nivel internacional. En su opinión, ¿cuál ha sido la aportación o las aportaciones que el Instituto de Investigaciones Jurídicas ha tenido en la vida política del país?

HFF : La principal aportación es la del conocimiento jurídico, el conocimiento académico riguroso, que se refleja en la producción de libros y artículos, así como en las relaciones que se cultivan con otras instituciones académicas del país y del extranjero.

Hay que recordar que este Instituto surgió en 1940 como Instituto de Derecho Comparado de México, fundado por un profesor español, don Felipe Sánchez Román, con la idea de que aquí se cultivara el derecho comparado, de que hubiera apertura hacia la 
comparación y hacia el exterior. Fue en una época en la que había ya una fuerte corriente de nacionalismo jurídico, o sea, que el nacionalismo no fue nada más el del cine, el muralismo o la literatura, sino que también hubo expresiones de nacionalismo en el campo del derecho, que son comprensibles en razón de nuestra historia y de lo que ha ocurrido en ella. Pero el Instituto siempre trató de cultivar una idea en la que México era central, pero nunca fuera de un contexto y de un horizonte más amplios. Cuando empezó un nuevo periodo de apertura del derecho hacia el exterior en los años ochenta y noventa, el Instituto ya había cultivado muchas de las ideas que luego fueron objeto de reformas constitucionales y legales. Para empezar, el doctor Fix Zamudio había estudiado, desde los años sesenta, al ombudsman, a los Consejos de la Judicatura y a los tribunales constitucionales. El tema de los derechos humanos, que hoy está en auge, se empezó a estudiar aquí, como tema académico, desde 1968. Con motivo del vigésimo aniversario de la Declaración Universal de Derechos Humanos se hizo un seminario en el Instituto, el cual tuvo que postergarse unos meses por el movimiento del 68, pero vinieron grandes personalidades del extranjero, como René Cassin, Premio Nobel de la Paz ese mismo año, así como numerosos profesores y alumnos de varios países. Del curso se publicó una memoria varios años después. Fue una semilla que sin duda tuvo importantes repercusiones más tarde.

La segunda aportación importante, creo yo, es que algunos investigadores del Instituto han fundado nuevas instituciones o han contribuido a su reforma, y por ello han cumplido un papel importante en la vida pública. Yo he reflexionado sobre eso y he llegado a la conclusión de que ha sido en circunstancias especiales, en las que el Estado ha perdido legitimidad -por ejemplo, porque el legislador está desprestigiado- cuando los juristas académicos pueden funcionar como un poder de reserva, cuando pueden ejercer un liderazgo 
que otras instituciones jurídicas - como la judicatura o la abogacía- no están en condiciones de asumir. Estos juristas cuentan al menos con un conocimiento técnico e imparcial, por lo que pueden tener la capacidad y la legitimidad para iniciar ciertos proyectos de reforma. Es posible que cuando estas circunstancias especiales desaparezcan, ya no se recurra a ellos y por eso tendrán que volver a encerrarse en sus cubículos.

AUB: Estoy de acuerdo con lo que acaba de mencionar y, en esa misma tesitura, ¿podría decirnos si considera que existen ciertos desafíos para el Instituto?

HFF: Desafíos los hay todos los días. Un desafío interno constante es el de la renovación de la planta académica. En los años en que yo fui director y en los que lleva en el cargo el doctor Pedro Salazar, ha ingresado al Instituto un número muy importante de investigadores. Aproximadamente la mitad de la planta de investigadores se ha renovado en los últimos doce años y eso es muy positivo, pues significa que el Instituto va a ser capaz de seguir trabajando como hasta ahora por mucho tiempo más. Ese es un gran desafío y creo que ha habido la capacidad de irlo resolviendo. También están los desafíos cotidianos del trabajo académico como la organización de eventos académicos, la búsqueda de recursos para las investigaciones, el dictamen y revisión de las publicaciones. Este instituto publica una cantidad impresionante de libros cada año y nuestro Departamento de Publicaciones casi no se da abasto para procesar las ediciones, lo cual, por un lado, es una buena noticia, pero, por el otro, a los autores luego nos frustra o desespera un poco que nuestro libro no sea el que sale más rápido.

Luego están los desafíos en relación con el orden jurídico externo. Yo pienso que los juristas somos reformistas casi por naturaleza. A mi parecer, quien se toma el derecho en serio no puede ser otra cosa más que reformista y tiene que creer en el gradualismo, porque 
sabemos que el derecho no se puede cambiar todo de un día para otro. La única manera de lograrlo es hacer una revolución, y aún las revoluciones tienen que pactar con el pasado y mantener cosas que vinieron antes. Al final, esto quiere decir que debemos defender las instituciones vigentes. Defenderlas no significa, desde luego, solamente alabarlas y decir que todo marcha muy bien, sino considerar que representan pasos importantes en dirección al logro de ciertas metas y determinados objetivos que tienen que estar anclados en el derecho, en el orden jurídico, y que los cambios que requieran se tienen que dar de manera ordenada y paulatina. A veces nos quejamos de que se ha reformado demasiado la Constitución, y sí, en efecto, hay muchas reformas que no eran estrictamente necesarias o que se podrían haber aprobado de otra manera. Pero, por el lado positivo, hay que reconocer que la idea del cambio parece empezar siempre por el orden jurídico, es decir, de que cualquier modificación importante en la vida nacional debe tener un anclaje en la Constitución, y cuando ese anclaje no existe, hay que crearlo. Por supuesto yo no comparto la idea de que en los últimos años no haya avanzado el país. Más bien el país ha cambiado bastante, dando pasos muy importantes a través de la renovación institucional. Si tenemos un compromiso real con el orden jurídico, debemos hacer una defensa imparcial y objetiva de lo que se ha logrado, criticando lo que presente debilidades y deficiencias, y estudiando y proponiendo las vías de perfeccionamiento del orden jurídico vigente.

AUB: Doctor, y en ese sentido que nos ha comentado acerca de los retos del Instituto, ¿cree que él podría seguir creciendo, o está en su la máxima capacidad?

HFF: El instituto no ha dejado de crecer. En el año de 1966, cuando la Junta de Gobierno nombró como director al doctor Fix Zamudio, había cuatro investigadores de tiempo completo; actualmente son más de cien. De ser un instituto pequeño en el área de 
humanidades, pasó a ser el segundo más grande, después del Instituto de Investigaciones Filológicas, que es un instituto que surgió por la agrupación de varios centros de estudios que siguen existiendo, como el Centro de Estudios Mayas o el Centro de Estudios Literarios. El problema de crecimiento en este Instituto es más bien de infraestructura física, ya que desde que yo terminé mi periodo en la dirección, no se veía hacia dónde pudieran crecer sus instalaciones, y en ese momento pensé que lo único que se podía hacer era adecuar los espacios interiores. Es lo que ha estado haciendo con audacia y buen tino el doctor Pedro Salazar en estos años. Si ustedes llegaron a visitar el Instituto hace unos cuatro o cinco años, advertirán con facilidad cuánto han cambiado las instalaciones, que se han modernizado y actualizado. También al doctor Salazar debemos el proyecto, que está en vías de hacerse realidad, de una sede del Instituto en la ciudad de Tijuana, enfocado principalmente en temas jurídicos de la frontera, lo cual ofrece una oportunidad más de crecimiento y diversificación. Yo no me atreví a emprender proyectos tan ambiciosos. Le dimos buen mantenimiento al edificio del Instituto y se hicieron algunos cambios innovadores, como el espacio en el Auditorio que ocupa la colección de búhos que nos legó el doctor Jorge Carpizo. No iniciamos un ejercicio de revisión radical de los espacios, pero los cambios actuales reflejan la evolución del trabajo jurídico. Las nuevas generaciones tienen otras ideas, otras capacidades y formaciones, y estoy seguro de que van a hacer un trabajo muy destacado.

AUB: Le agradezco, doctor. En relación a la producción científica que se realiza en este Instituto -que es un foco muy importante para el país- casi la totalidad se replica en todos los estados. Particularmente, ¿cómo considera usted que se podría mejorar el nivel de investigación y el nivel educativo en el país? 
HFF : Más allá del tema de los recursos materiales o económicos, que siempre son una limitante, yo creo que no hay falta de vocación por la investigación fuera de esta ciudad. Cuando yo era director tenía preparada siempre una lista de unas veinte personas que consideraba de interés para incorporarlas a nuestra planta académica, pero nunca hubo el número suficiente de plazas para hacerlo. Yo entiendo, y ello es motivo de orgullo, que quienes quieren dedicarse a la investigación jurídica piensen en primera instancia en ingresar en este Instituto, pero lo cierto es que no hay ni habrá oportunidades para todos ellos. Por fortuna, ya hay otras oportunidades interesantes tanto dentro como fuera de Ciudad de México, y algunas de ellas han sido aprovechadas por estos investigadores de la lista a la que me refiero. Veo, sin embargo, que hay un número creciente de jóvenes que comienzan, en México y en el extranjero, sus estudios de doctorado en derecho (y ciencias sociales afines), que es el requisito mínimo que ahora hay que cubrir para iniciar una carrera en la investigación académica en el campo jurídico, es decir, la demostración de que se puede realizar investigación rigurosa y original. (En mi época no se había establecido todavía ese requisito y gracias a eso pude comenzar mi carrera de investigador sin haber obtenido todavía el doctorado). Me pregunto si habrá suficientes oportunidades para ellas y ellos, una vez que concluyan el gran esfuerzo, que toma varios años, de realizar estudios serios de doctorado y de obtener el grado respectivo. Posiblemente no habrá tantas oportunidades, y menos aún en el actual clima de austeridad y de recorte de recursos a la ciencia y la tecnología.

La segunda condición, que es muy importante para que haya investigación exitosa, es la continuidad en el largo plazo, y ese es un punto en el que creo que el Instituto ha sido ejemplar, en el sentido de que ha perseverado ya casi ochenta años en la ruta de la investigación y la única manera de llegar al punto en el que esta- 
mos, es haber invertido todo este tiempo un gran esfuerzo para lograr el cambio con continuidad. Considero que todos los directores que ha tenido este Instituto han seguido con persistencia la misma ruta, consistente en abrir nuevos temas de investigación, en estudiar cuestiones de relevancia para la vida del país, en adelantarse a las reformas. Esto es algo que muchas veces ha fallado fuera de Ciudad de México, por falta de continuidad. Se han creado ahí numerosos grupos de investigación, institutos y centros, programas de posgrado. El problema es que cuando hay algún conflicto o cuando cambian los responsables de la dirección o coordinación, estos esfuerzos no continúan. Pienso que esta limitación empieza a superarse poco a poco. Como decía yo antes, la investigación es celosa; requiere una inversión de recursos humanos y materiales de largo aliento, la acumulación de resultados y el trabajo que se apoya siempre en lo ya logrado. Repito que en las últimas cinco décadas, cuando menos, cada director ha fijado prioridades y ha tratado de realizar sus propuestas particulares, pero en general se ha seguido una línea de continuidad muy consistente, conforme a la cual el conocimiento generado por la investigación es muy importante para alimentar la renovación del orden jurídico.

AUB: Hablando también acerca del trabajo que requiere la continuidad y la persistencia, no solamente de los investigadores, sino también en un ámbito administrativo, me voy a referir específicamente a su administración en el Instituto de Investigaciones Jurídicas, en particular, todo lo que usted logró en ese tiempo como director, ¿cuál cree que ha sido el legado de su administración?

HFF : No me atrevería a decir legado. Quizá me tocó cerrar un periodo e iniciar la transición hacia uno nuevo. La época que se cierra es el largo periodo que se inicia en 1966 con la dirección del doctor Fix-Zamudio, quien fue el primer director de tiempo completo. Hasta ese momento los directores habían sido académi- 
cos distinguidos, pero que desempeñaban también otras funciones y tenían otras responsabilidades, dentro y fuera de la Universidad. Además de ejercer la dirección de tiempo completo, el doctor Fix Zamudio tuvo la oportunidad de iniciar la formación de una nueva generación de jóvenes académicos, entre quienes se encontraban el doctor Ricardo Méndez Silva, el doctor Rolando Tamayo y Salmorán, la doctora Patricia Kurczyn y los doctores Jorger Carpizo y Diego Valadés, exdirectores del Instituto, por mencionar solamente a algunos. Esta generación es ahora la más antigua del Instituto y varios de sus integrantes ya se han jubilado o están en proceso de hacerlo.

Cuando yo tomé la dirección del Instituto, decidí no estorbar y apoyar en cambio todos los proyectos y todas las ideas que fueran viables. Dicho en otras palabras: no se trataba de realizar mis propias ideas, sino de promover y apoyar lo que se estaba haciendo bien en el Instituto. Si reviso los programas de trabajo con los que me presenté ante la Junta de Gobierno de la Universidad, tendría que reconocer que no logré hacer o impulsar mucho de lo que ofrecí, porque sencillamente ya era un desafío considerable mantener una dinámica de trabajo tan intensa como la que ha habido en el Instituto durante muchos años.

Quizá la aportación más novedosa de mi parte fue la convocatoria a formar las primeras "líneas de investigación institucionales", que abordarían problemas transversales a las tradicionales áreas de investigación (derecho constitucional o derecho penal, por ejemplo), formadas por investigadores de varias especialidades, tanto de dentro como de fuera del Instituto. Esta propuesta ha continuado y se ha consolidado en el periodo actual, lo cual me produce mucha satisfacción, pero no reclamo gran mérito en su establecimiento, pues es la manera habitual de trabajo en la mayoría de los centros e institutos de investigación del mundo. 
La otra contribución importante, si se puede hablar de tal, es la incorporación de más de treinta investigadores e investigadoras durante los ocho años en que ocupé la dirección. Hubo jubilaciones, fallecimientos y renuncias que obligaron a ocupar las plazas vacantes y hubo también creación de algunas plazas nuevas más, dando, como he dicho, un total de más de treinta plazas ocupadas, casi todas a propuesta mía, con aprobación de las instancias colegiadas de la Universidad. Algunas fueron ocupadas por distinguidos colegas que retornaron al Instituto después de cumplir importantes funciones fuera de la Universidad; en otros casos, se trataba de académicos consolidados que deseaban continuar su carrera en nuestro Instituto; finalmente, hubo un número importante de jóvenes, especialmente mujeres, que se incorporaron para iniciar una carrera propia, y vemos ahora que están rindiendo frutos apreciables.

En resumen: diría sencillamente que me tocó hacer lo necesario para que el Instituto pudiera continuar sus trabajos con la intensidad y la dinámica que ya venían de antes, aunque al final los números totales del periodo me sorprendieron. Por ejemplo, en el último informe contabilicé más de 120 instituciones, nacionales y extranjeras, con las que se realizó alguna coedición, y en los ocho años aparecieron más de dos mil publicaciones. No tengo duda de que estos números van a ser rebasados por la dinámica del periodo actual.

AUB: Parece fácil decirlo, pero realmente esa productividad académica es impresionante. Considero que hay una dinámica cada vez más rigurosa en torno a la productividad, especialmente en el ámbito científico; las evaluaciones de los investigadores cada vez son más rigurosas, cada vez se necesita tener más impacto. En ese sentido, doctor, en su momento tuvo doble labor, de investigador y director, podría indicarnos, de las producciones que llevó a cabo, ¿cuál considera que es su obra más representativa? 
HFF : Es difícil decirlo; la verdad es que no tengo muchos libros propios, de autoría única. Sin embargo, siento satisfacción por el hecho de que el tema de mi tesis doctoral, publicada en inglés en 2003 y en español en 2006 (Tribunales, justicia y eficiencia. Estudio sociojurídico sobre la racionalidad económica en la función judicial, México, UNAM), siga siendo relevante y actual para nuestro país, más de veinte años después de que la presenté en Bremen (1998). Probablemente eso no ocurre con muchas tesis de doctorado. Un proyecto en el campo del derecho constitucional que me motivó mucho fue el de reordenación y consolidación del texto de la Constitución de 1917, que compartí con otros colegas del Instituto. Hasta ahora no nos han tomado en serio, salvo en el Estado de Colima, que celebró los cien años de su Constitución, justamente en 2017, con un texto renovado que fue sometido a la metodología que hemos propuesto en el Instituto.

Yo empecé mi carrera de investigador con la idea de realizar una descripción de la realidad del sistema jurídico mexicano, porque en ese entonces no había casi nada en esa línea. Junto con el doctor Sergio López Ayllón, actual director del Centro de Docencia e Investigación Económicas (CIDE), empezamos a construir el primer piso de la casa socio-jurídica. Se trataba de hacer una primera descripción del campo recurriendo a estadísticas, judiciales y de otro tipo, así como a cualquier material que pudiera decirnos algo sobre la realidad del derecho en nuestro país. También empezamos a construir el segundo piso cuando tratamos de reflexionar, con inclinación más teórica, sobre el significado de lo que estábamos describiendo. Pensamos, por ejemplo, que el derecho ha cambiado de función en la sociedad mexicana, que ha habido una "transición jurídica", al menos en el sentido de que su uso se ha ampliado y se ha vuelto central para ciertos sectores sociales. El mejor ejemplo es el cambio en el papel del Poder Judicial. Hace 25 años, la Su- 
prema Corte realizaba una labor importante, pero relativamente marginal en el espacio público. Ahora se encuentra en el centro de este espacio, donde la toca resolver controversias de gran alcance, determinando, por ejemplo, si algunas de las políticas que pretende impulsar el Ejecutivo son compatibles o no con la Constitución.

En estos años, otros investigadores, principalmente jóvenes, han empezado a hacer estudios empíricos similares. Muchos no son juristas, sino cultivadores de otras ciencias sociales, como la economía, la ciencia política y la antropología, por lo que cuentan con la ventaja de una formación especializada que brinda la posibilidad de usar herramientas de investigación que en general no ofrecen las escuelas y facultades de derecho. Los juristas de mi generación somos todavía aprendices de científicos sociales y ahora enfrentamos una intensa competencia, que es sana y que ha redundado en que, cada año, tengamos un mejor conocimiento de cómo funciona el derecho mexicano. Por tanto, seguimos construyendo el segundo piso de la casa socio-jurídica. Contamos ahora con la posibilidad de hacer diagnósticos, por ejemplo, de cómo funcionaba el sistema penal anterior y de cuál es, en comparación, el desempeño del modelo acusatorio.

Este interés por acercarse a la ciencia social y por utilizar sus herramientas me parece que es característico de mi generación y de las generaciones más jóvenes, a las que ya no les parece suficiente conocer las normas para entender lo que pasa en el mundo del derecho, sino que resulta necesario marcar un horizonte más amplio, en el que las ciencias sociales tienen un lugar importante.

Algo similar ha ocurrido del otro lado. En los años sesenta el marxismo estaba en auge y para esta escuela de pensamiento el derecho no era particularmente importante. Ahora los científicos sociales han descubierto que esto no es así y que el derecho no es una mera superestructura de la sociedad, sino parte constitutiva 
del orden social. Este derecho realmente existente no coincide por fuerza con lo que se publica en el Diario Oficial, pero no hay duda de que hay una revalorización clarísima del derecho desde la ciencia social y eso es algo muy positivo. En ese sentido no quisiera verme como pionero, pero hace 28 años éramos muy pocos los que teníamos esa idea.

AUB: En esa misma perspectiva y desde un aspecto sociológico-jurídico, en el que usted es el experto, me quisiera referir a los problemas que existen actualmente en la sociedad: ¿cómo es que podríamos verlos desde esta perspectiva sociológica y hasta donde podríamos enumerar o mencionar algunos de estos problemas a los que nos enfrentamos y hasta donde la sociología jurídica podría aportar a esos problemas?

HFF: Me parece que tenemos un problema importante de respeto por el orden jurídico y la legalidad. Desde luego esto no es nuevo, pero creo que el problema se ha agravado porque, mientras tuvimos una Presidencia todopoderosa y hegemónica, los hilos del control social estaban también relativamente atados y firmes. No es que no hubiera delincuencia, pero ésta estaba acotada y controlada por el régimen político. Probablemente permeaba en algunas capas minoritarias de la población la importancia de las leyes, pero como demuestra la investigación del profesor Gessner a fines de los años sesenta, en general el contacto del grueso de la población con el derecho era mínimo y, cuando lo había, no necesariamente era un contacto positivo. En gran medida esto sigue siendo así.

Guando por efecto del cambio político la Presidencia dejó de ser todopoderosa (aunque ahora vemos un intento de restauración de su antiguo poder), también se soltaron los hilos del control social y se dispararon la delincuencia y la impunidad. ¿Por qué? En retrospectiva podemos ver que había una Presidencia fuerte, pero no un Estado fuerte, es decir, no hubo necesidad de construir nuevas 
y fuertes instituciones sino hasta cuando se debilitó el poder presidencial. En ese proceso nos encontramos. Las nuevas instituciones no acaban de consolidarse porque ello requiere grandes esfuerzos y toma tiempo. Mientras tanto, los órganos de la justicia se ven rebasados, sin capacidad de respuesta, principalmente las procuradurías y fiscalías, que inician cientos de miles de carpetas de investigación (y ello apenas sobre una fracción muy menor del total de delitos cometidos), pero muy pocas llegan a alguna resolución y menos aún desembocan en una sentencia condenatoria. El mensaje que se envía a la sociedad es claro: la impunidad es casi total y la gente soporta la ilegalidad con espíritu estoico, pues ya nadie está a salvo de ella.

Para ejemplificar: tengo con mi familia una casa de descanso en el Estado de México. La semana pasada se metieron varias personas a robar, y aunque no se llevaron cosas de gran valor económico (sino acaso afectivo), se genera una sensación de vulnerabilidad, mientras que lo único que se podrá lograr es la indemnización que pueda ofrecer el seguro, cuando se cuenta con alguno. Algunos vecinos ya pusieron un letrero a la vista con el mensaje de que a los sospechosos que detengan no los entregarán a la policía. Es un mensaje muy fuerte, pero cada vez más común: a la ilegalidad de la delincuencia sólo logramos oponer la justicia por propia mano, que no deja de ser ilegal también. Pienso que eso es preocupante y no veo que se pueda resolver sin invertir tiempo y dinero en la creación y desarrollo de las instituciones, como las policiales. El gran problema del país siguen siendo las instituciones y si no lo vemos así no vamos a resolver muchas de nuestras dificultades, empezando por la del respeto a la legalidad. Me temo que ésta no es la visión que prevalece en el nuevo gobierno; tienen otra, que es legítima porque con ella ganaron las elecciones, pero considero que en eso están profundamente equivocados. 
AUB: Siguiendo los temas más álgidos que existen, me voy a referir a uno internacional. Existe una crisis global en términos de una ola migratoria hacia ciertas zonas muy específicas, ¿cree usted que algo se pueda aportar, desde una perspectiva jurídica, a los recientes problemas relacionados con la xenofobia, el racismo o en particular la aporofobia? ¿Qué tanto está repercutiendo este problema en el ámbito jurídico y cómo va cambiando?

HFF: El derecho, a pesar de ser indispensable en la vida social, tampoco es capaz de resolver muchas cosas. Es obvio que en materia migratoria debe haber leyes que digan quién puede entrar o no en el territorio de un país soberano. Cuando se hace de manera ilegal o irregular, esas leyes deben determinar cómo van a actuar las autoridades competentes, qué procedimiento o derechos tienen a su alcance, para defenderse, las personas involucradas, etcétera. Además de las leyes nacionales hay convenciones y tratados internacionales sobre la materia. Pero vemos con claridad que la política se impone de manera brutal y por encima de lo que digan las leyes, lo que es preocupante y, podríamos decir, hasta triste. Las leyes tienen una finalidad educativa; la gente conoce en general qué es lo que no está permitido, lo que está prohibido, pero cuando entran en juego poderosos intereses políticos o económicos, que explotan y se aprovechan de las necesidades e incluso la desesperación de la gente, el cumplimiento de las leyes se tuerce y se posterga. Esto no ocurre nada más en la migración, sino en muchos otros ámbitos sociales. Se da entonces el dilema de que, por un lado, las leyes son indispensables en la vida social, para establecer un orden que evite la "guerra de todos contra todos", pero, por el otro lado, esas leyes no logran mucho por sí mismas si detrás de ellas no hay fuerzas igualmente poderosas que impulsen su cumplimiento. Si hay una sociedad civil organizada que puede protestar con fuerza, podríamos ver que probablemente los intereses políticos y económicos re- 
trocedan o vean la manera de llegar a un compromiso con los intereses contrapuestos, pero al final seguimos viviendo en la sociedad humana la cuestión de que, en última instancia, el más fuerte es el que prevalece en la mayoría de los casos.

AUB: Para finalizar - no quisiera abusar de su tiempo- me gustaría pedirle alguna recomendación para los nuevos juristas, en particular para los nuevos investigadores, algo que pueda darnos como mensaje a los que estamos comenzando una carrera académica.

HFF : Para poder perseverar en la carrera académica se necesita, como en cualquier otra vocación, sentir pasión por lo que se hace. Hay quien se puede dedicar a la investigación sin tener esta mística y puede hacerlo muy bien, como trabajo puramente profesional, pero yo creo que es importante sentir pasión y eso se tiene o no, y no sé si se pueda crear por uno mismo. Lo segundo, muy importante, es mirar hacia las ciencias sociales. No estoy diciendo que se desatienda la formación tradicional en derecho; la ciencia jurídica va a seguir siendo lo que es mientras haya Diario Oficial y semanarios de jurisprudencia, es decir, textos normativos que sistematizar, interpretar y aplicar. Al mismo tiempo, necesitamos un horizonte de entendimiento más amplio y eso es algo que nos pueden aportar las ciencias sociales. Por ejemplo, a mí me ha hecho falta la formación en métodos estadísticos, y ello limita seriamente mi capacidad de hacer ejercicios cuantitativos, salvo los muy básicos. Por fortuna, en muchas escuelas y facultades de derecho ya se ofrecen el análisis económico y la estadística como herramientas básicas del trabajo jurídico. La historia también es muy importante. Estoy convencido de que el jurista que carece de formación histórica en su materia, entiende si acaso la mitad de lo que implica su campo profesional. Por ejemplo, para comprender realmente al juicio de amparo y por qué es actualmente como es, tenemos que saber todo lo que pasó con esta institución desde mediados del siglo XIX. Solamente así 
estaremos en posibilidad de pensar y hacer algo distinto con él. Entonces, considero que con esas tres herramientas - la ciencia jurídica, más las bases, los métodos y las técnicas de investigación social (en sociología, economía, ciencia política), más una conciencia histórica importante--, se tienen las herramientas indispensables para hacer investigación jurídica.

Lo tercero, como ya he dicho, es perseverar. Si me pongo a revisar los primeros trabajos que publiqué, no diría que me dan vergüenza, pero son mucho más sencillos o limitados en comparación con lo que puedo hacer ahora, sin que tampoco piense que mis aportaciones actuales son gran cosa. El investigador tiene que trabajar con cierta independencia de si tiene buena o mala recepción lo que hace. No obstante, la evaluación del trabajo académico se ha vuelto más rigurosa. En ese sentido, la investigación ha cambiado mucho desde que yo inicié mi carrera.

Así lo pude ver en los años que me tocó formar parte del Consejo Técnico de Humanidades. Hubo una época en la que la revisión y aprobación de los informes de labores de los investigadores se manejaban como algo rutinario y burocrático. Ahora se revisan con cuidado. En el Instituto contamos con un sistema para valorar en puntos el trabajo académico y se exige que cumplamos con un número mínimo de puntos al año. El Sistema Nacional de Investigadores, con todos sus defectos, ha propiciado que cada vez sea más rigurosa la investigación. Actualmente sí hay que estar muy bien preparado, ya que el diletantismo va de salida. Yo diría entonces: hay que prepararse; hacer un buen doctorado; no desanimarse si no surgen las oportunidades rápidamente; ver que en el país ya hay más opciones que la UNAM o que en la Ciudad de México, y que las condiciones de desempeño de los académicos no son malas. Una ventaja que tiene la carrera académica, al menos en la UNAM, es una gran libertad, lo cual no significa que no haya esfuerzos para 
dirigir el trabajo académico a cierto tipo de metas y objetivos, y por eso el Instituto ha realizado muchos proyectos colectivos importantes. Tal vez las remuneraciones no sean ideales al comienzo, pero conforme pasa el tiempo se ve una mejora. Ahora se pagan labores académicas que antes no se pagaban, como los cursos y las conferencias. Juntando todo esto, creo que en la comparación de las remuneraciones promedio que hay en el país, al académico no se le presentará ningún problema. Claro, empiezan otros tiempos y otras exigencias, pero esperamos que el trabajo académico siga siendo atractivo y que nosotros, que ya tenemos bastante antigüedad en él, podamos seguir renovando nuestros esfuerzos por un tiempo más.

AUB: Muchísimas gracias, doctor, la verdad es que ha sido muy interesante y apasionante escucharlo. Me complace muchísimo haber estado aquí con usted, espero volver a conversar con usted pronto.

HFF: Con mucho gusto, gracias a usted. 
